Protestantismo em Revista é licenciada sob uma Licença Creative Commons.

http://dx.doi.org/10.22351/nepp.v45i1.3521

\title{
TODA IGREJA PRETENSAMENTE MISSIONAL DEVE SER MISSIONÁRIA
}

\author{
All calls missionary Church must be missionary
}

Silas Fiorotti ${ }^{*}$

\section{RESENHA}

\section{CARRIKER, Timóteo. O que é igreja missional: modelo e vocação da igreja no Novo} Testamento. Viçosa: Ultimato, 2018, 128pp.

Timóteo Carriker é teólogo e missionário norte-americano radicado no Brasil, reside no país desde 1977. Entre os mais diversos teólogos do meio evangelical brasileiro, ele é um dos poucos especialistas em missões que possui uma boa formação e que dialoga com referenciais que raramente são lidos ou recomendados nos seminários evangélicos. Por exemplo, ele mesmo foi orientado pelos teólogos Arthur F. Glasser ${ }^{1}$ e David J. Bosch. ${ }^{2}$ Ainda cabe destacar que ele leciona em seminários e escolas de missões e é colunista da revista Ultimato.

Como o próprio título do livro indica (O que é igreja missional), T. Carriker buscou esclarecer o que seria uma igreja missional. Na introdução, intitulada Igreja missionária ou igreja missional (pp. 13-24), ele faz uma breve sinopse da utilização do termo missional na teologia. Mesmo citando alguns teólogos e movimentos que estariam dentro do debate em torno deste termo, Carriker sinaliza a adoção da perspectiva do movimento The Gospel and Our Culture Network (GOCN) ${ }^{3}$ que, por sua vez, propõe que as reflexões bíblicas e teológicas

[Texto recebido em novembro de 2018 e aceito em dezembro de 2019, com base na avaliação cega por pares realizada por pareceristas ad hoc]

* Doutor. Professor, pesquisador colaborador do CERU-USP e do CERNe-USP, e coordenador do projeto Diversidade Religiosa em Sala de Aula. Realizou pesquisa de doutorado sobre o pentecostalismo em Moçambique. E-mail: silas.fiorotti@gmail.com.

1 Arthur F. Glasser (1914-2009), nascido nos EUA, foi teólogo, missionário e professor do Fuller Theological Seminary. Autor de diversos livros e artigos, entre eles: o livro Announcing the Kingdom (Baker Academic, 2003).

2 David J. Bosch (1929-1992), nascido na África do Sul, foi teólogo, missionário e professor da University of South Africa. Autor de diversos livros e artigos, entre eles: o livro Missão transformadora (2. ed. Sinodal, 2007).

3 Ver: <https://gocn.org/>. 
não podem prescindir de prévias reflexões sociológicas. Neste sentido, ele propõe uma ordem da chamada hermenêutica missional:

(...) começa com a avaliação sociológica, informa-se pelas narrativas bíblicas mais abrangentes ou pela teologia bíblica e depois encontra a sua forma final pela avaliação e, ou, revisão de categorias teológicas. (p. 20)

No primeiro capítulo, intitulado Dois valores fundamentais (p. 25-36), T. Carriker buscou fazer essa avaliação sociológica dos primeiros 350 anos do cristianismo. Sem nenhum tipo de ressalva ou crítica, ele adota a perspectiva do sociólogo norte-americano Rodney W. Stark, ${ }^{4}$ um dos expoentes da teoria da escolha racional da religião, sobre o cristianismo primitivo. Esta teoria enfatiza o papel da agência humana nos processos religiosos, mas trabalha com uma forma restrita de racionalidade e trata os compromissos religiosos simplesmente como ações auto-interessadas. ${ }^{5}$ Neste sentido, Carriker conclui que o crescimento do cristianismo primitivo deveu-se acima de tudo aos "vínculos a novas redes interpessoais de interação" (p. 28), algo que supostamente seria fruto do conteúdo da mensagem cristã resumida em dois valores essenciais: a graça de Deus e o amor ao próximo.

Nos capítulos 2 a 6 (p. 37-73), Carriker buscou abordar algumas práticas específicas de cinco igrejas neotestamentárias, intituladas por ele de igrejas missionais: de Antioquia, de Roma, de Filipos, de Éfeso e de Jerusalém. Destaca-se que ele exalta o fato de haver lideranças múltiplas, plurais e diversificadas nestas cinco igrejas, algo que necessariamente não prejudica a unidade dos crentes e que faz muita falta atualmente: "As igrejas atuais carecem muito de uma visão de liderança múltipla e diversificada" (p. 41). Além de outras características, Carriker aponta principalmente que estas igrejas neotestamentárias, consideradas missionais por ele, eram também igrejas missionárias: com "missão cósmica", que realizavam "trabalho em equipe", com "equipes missionais" esforçadas, que buscavam "novos lugares", que tinham "foco da ação para fora", etc. Com isso, ele de alguma forma conclui que toda igreja missional possui alguma visão missionária.

No sétimo capítulo (p. 75-103), Carriker buscou analisar algumas práticas da igreja (ou igrejas) da Galácia, mas sem considerá-la efetivamente uma igreja missional. A partir de uma leitura da Carta aos Gálatas, esta igreja não foi considerada missional porque ela supostamente não assimilou o princípio da graça de Deus, supostamente não apresentou uma visão missionária e, por isso, foi exortada pelo apóstolo Paulo. Na conclusão (p. 105111), Carriker retoma as características que supostamente levam uma igreja a ser considerada missional e conclui: “(...) a igreja missional no Novo Testamento era também missionária. Preocupava-se em alcançar as suas vizinhanças e em anunciar o evangelho em regiões e povos mais distantes" (p. 110).

4 Rodney W. Stark é sociólogo norte-americano, um dos expoentes da teoria da escolha racional da religião, e foi professor da University of Washington. Autor de diversos livros e artigos, entre eles: o livro $O$ crescimento do cristianismo (Paulinas, 2006) e o livro The Triumph of Christianity (HarperOne, 2011).

5 Para uma avaliação crítica da teoria da escolha racional da religião, ver o artigo Usos e limites da teoria da escolha racional da religião de Ricardo Mariano (in Tempo Social, São Paulo, v. 20, n. 2, 2008, p. 41-66). 
Após a leitura, considero que não é exagero dizer que falta crítica à hermenêutica proposta por Carriker. A análise do mundo social do cristianismo primitivo ficou muito restrita, ${ }^{6}$ a ideia de que as escolhas religiosas estão relacionadas às ações autointeressadas não foi devidamente discutida em diálogo com as leituras neotestamentárias, e também não foi devidamente discutida a ideia de que a missão cristã depende mais de esforço e de persistência do que de qualquer estratégia em si. Por exemplo, a perspectiva adotada da teoria da escolha racional tende a valorizar de forma excessiva o papel das lideranças, mas como fica o papel dos leigos no cristianismo primitivo? Por que não propor também modelos missionais protagonizados por leigos? Contudo não deixa de ser cativante a defesa da ideia de que toda igreja pretensamente missional deve ser também missionária, deve ter a visão de que a missão cristã possui dimensões cósmicas. Ou seja, toda igreja pretensamente missional deve se comprometer com o combate às injustiças de perto e com o combate às injustiças de longe.

6 Diversos pesquisadores e pesquisadoras têm buscado compreender o mundo social do cristianismo primitivo. Pode-se citar os seguintes nomes: Eduardo Arens, Karl P. Donfried, James D. G. Dunn, Richard A. Horsley, Helmut Koester, Wayne A. Meeks, Ben F. Meyer, Paulo A. S. Nogueira, Luise Schottroff, Gerd Theissen, entre outros. 